\title{
Fatigue damage evolution in GFRP laminates with constrained off-axis plies
}

\author{
J.A. Glud ${ }^{1}$, J.M. Dulieu-Barton ${ }^{1,2}$, O.T. Thomsen ${ }^{1,2}$ and L.C.T. Overgaard ${ }^{1}$ \\ ${ }^{1}$ Department of Mechanical and Manufacturing Engineering, Aalborg University \\ Fibigerstraede 16, 9220, Aalborg Oest, Denmark \\ Email: \{jag,ott,lcto\}@m-tech.aau.dk, web page: www.m-tech.aau.dk
}

${ }^{2}$ Faculty of Engineering and the Environment, University of Southampton

Highfield, SO17 1BJ, Southampton, United Kingdom

Email: \{janice,o.thomsen\}@soton.ac.uk,web page: www.southampton.ac.uk/engineering

Keywords: Fatigue, Polymer-matrix composites, Transverse cracking, Damage mechanics, Digital image processing

\begin{abstract}
The characterisation of fatigue damage evolution in constrained glass fibre reinforced plastic offaxis laminates is presented. A newly developed imaging technique known as Automatic Crack Counting (ACC) is used to quantify the off-axis crack state in constant amplitude (CA) and variable amplitude (VA) block loading tension-tension fatigue tests and constant amplitude compressiontension tests. The quantified crack states are analysed by combining the newly developed ACC method with a data mining approach and applying these to large data sets obtained during fatigue tests. It is shown that for a constant stress level, the stochastic nature of off-axis crack initiation and crack growth is accurately modelled by the Weibull distribution, with the distribution parameters being efficiently derived using the developed approach. The data-rich characterisation provides new insight in the crack density evolution process for VA and C-T loading, as well as derived Weibull distribution parameters in combination with the classical S-N curves and Paris’ Law relationship. Hence, providing an improved approach that includes the stochastic and deterministic information for physically based modelling of crack density evolution for fatigue loading.
\end{abstract}


Glud, J.A., Dulieu-Barton, J.M., Thomsen, O.T. and Overgaard, L.C.T., "Fatigue damage evolution in GFRP laminates with constrained off-axis plies”, Composites Part A, http://dx.doi.org/10.1016/j.compositesa.2017.02.005

\section{Introduction}

Laminated polymer based composite materials or fibre reinforced polymers (FRP) are being used increasingly in structural components subjected to fatigue loading. Accurate predictions of the material failure are essential for reliable and weight efficient structural design. The fatigue life prediction of FRP has been the subject of significant interest for more than three decades, and the fatigue damage modes observed in FRP laminates are generally well understood in qualitative terms, e.g. [1]. In pristine layered Multi-Directional (MD) laminates, the first damage mode usually takes the form of off-axis cracks tunnelling through the laminate layers, followed by delamination and fibre breakage leading to ultimate structural failure. This failure sequence has been reported by several authors on the coupon scale [2-4] and on the structural scale [5], where it was clear that a predominant failure mode of a wind turbine blade subjected to fatigue loading was off-axis cracks, although not specifically mentioned by the authors. It is particularly important to predict the offaxis crack damage mode, since these cracks promote other damage modes such as delamination and fibre breakage $[6,7]$ and are linked directly to the stiffness degradation observed in composite laminates during fatigue loading [3, 4, 8, 9].

Classically, the rate of fatigue damage development is described on the macroscopic scale in terms of strength by utilising S-N curves and in terms of crack propagation thresholds by utilising Paris’ law relationships. S-N curves and Paris’ law relationships are established from a set of phenomenological material constants resulting in fatigue limits and threshold limits for crack propagation, i.e. fatigue failure parameters, which are determined using a prescribed fatigue characterisation method. In the very early work [10] a fatigue characterisation method and a failure criterion distinguishing between failure in the matrix and the fibres were proposed, where the matrix failure corresponded to the off-axis crack damage mode. The fatigue failure parameter identification method in [10] consisted of a set of S-N curves, which required extensive testing on Uni-Directional (UD) laminates, to produce needed material input to a stress based 
phenomenological fatigue model. The ideas presented in [10] have resulted in extensive testing campaigns on UD material systems, e.g. [11], to provide a basis for material input to fatigue models. However, a recent detailed review of phenomenological fatigue models [12] concluded that for some load cases the proposed fatigue criteria give non-conservative predictions. The reason for the non-conservative predictions could not be determined, as the models reviewed in [12] did not account for the actual physical damage mechanisms. To model the actual damage mechanisms, a branch of fatigue models known as 'progressive continuum damage models' have been proposed [13-17], where fatigue damage is modelled at the ply thickness scale. The models are based on phenomenological quasi-static failure criteria and as with the fatigue models also involve extensive characterisation of UD materials systems to calibrate the empirical constants. The models show good predictive capabilities on the tested materials, but the empirical nature of such models may question their general applicability and validity. An explanation for the shortcomings of the phenomenological models described in [12], and why progressive continuum damage models require calibration of several empirical constants, is provided in the present paper. Here it is considered that the fatigue failure parameters derived from UD laminates are not representative for the case when the UD plies are combined and constrained to form a MD laminate. This is because, as described in [18], the damage progression in a UD ply embedded in an MD laminate is different to that of a UD ply embedded in a UD laminate. In a laminate consisting entirely of UD plies unstable propagation of a single crack occurs, which is not accompanied by progressive stiffness degradation prior to final failure. When constraining plies are present, as is the case for UD plies embedded in MD laminates, stable crack propagation is observed, resulting in a progressive stiffness degradation of the laminate during the testing. Therefore, fatigue tests on UD laminates cannot provide sufficient fatigue failure parameters to model the progression of actual damage mechanisms in MD laminates. Hence, in the present paper, a new way to inform fatigue models and 
provide general applicability, whilst limiting the need for empirical constants, is proposed by quantifying the off-axis crack evolution process throughout fatigue tests and derive material parameters from measurements on MD laminates.

Alongside fatigue models, micro-mechanical modelling represents a promising tool to describe the influence of the current damage state of an MD laminate on the overall structural performance. In [19] an overview and classification of available micro-mechanical damage models was provided. From the findings in [19] it is clear that micro-mechanical models generally predict the degraded constitutive properties of arbitrary laminates solely from information on the volume density of offaxis cracks in each layer. However, the models do not include a means of predicting the off-axis crack evolution, which renders them less useful for design of real layered composite structures. In [20-22] attempts have been made to extend micro-mechanical models to describe fatigue damage, but studies have been limited because of the material data found in literature generally focuses on characterisation of UD plies and laminates.

Several fatigue test campaigns have been devoted to the study of off-axis crack density evolution in GFRP MD laminates for CA loading with constant load ratio [2-4, 6, 9, 23, 24]. Based on results from literature it is clear that the crack density evolution rate and saturation value increases when the load amplitude is increased. Further on, the evolution rate and saturation value is reduced when the off-axis angle of the constrained ply decreases. It should be noted that, there is a lack of data in the open literature where the influence of the load ratio and VA block loading on the crack density evolution in GFRP is reported.

The process of off-axis crack initiation has been quantified for CA loading and constant load ratio for different multiaxial stress states [3, 6, 9, 18]. Measurements on the number of cycles to initiation of the first few cracks are obtained by manual and visual assessment of the damage state. Reported 
results show that the number of cycles to initiation of the first few off-axis cracks is well described by the classical S-N power law curve.

Crack growth rates (CGR) for the stable propagation of off-axis cracks under CA loading with constant load ratio have been reported in $[8,9,18,25]$. In $[8,25]$ the CGR of off-axis cracks throughout the fatigue test were manually measured and it was found that the CGR were independent of crack length but dependent on stress level and crack density. The CGR increased with increasing stress level and decreased with increasing crack density, where the latter is known as the 'shielding effect' of off-axis cracks [9]. In [9, 18] CGR results for the first few noninteracting cracks were reported and it was shown that the CGR for off-axis cracks can be described by a Paris’ Law like relationship.

Based on the experimental results reported in literature described above, it is evident that there is a general agreement that the off-axis crack evolution can be described by initiation and the stable growth of cracks until a certain saturation point is reached. However, it is also clear that there is no general agreement on which fatigue properties should be derived or how they should be determined. The result is that fatigue studies cited in literature focus on either crack growth or crack initiation. Consequently there is little reported work that covers both crack growth and initiation $[9,18]$, or work that accounts for the interaction of the cracks. Furthermore, a major consideration is that in all previous work reported in literature [2-4, 6, 8, 9, 18, 23-25], the crack state quantification procedures were carried out by manually and visually counting cracks. The crack state generally consists of many cracks which are unevenly distributed in the region of interest, so the crack counting task is labour intensive and difficult, essentially because the images are difficult to analyse by eye e.g. [9, 26]. This limits the scope and size of studies and leads to a relatively poor temporal resolution of the crack state. Moreover, as a result of the complex images of the crack state, the 
manual counting procedure is prone to human errors where cracks are not counted in a consistent manner for all tests.

There is a clear need to devise a new approach to derive statistically representative fatigue failure parameters from MD laminate tests. With this aim in mind, an approach has been devised known as the Automatic Crack Counting (ACC) procedure [26], which quantifies the crack state for each ply in terms of the length and location for each individual crack for every processed image. The ACC procedure has allowed the collection of the necessary data sets without human errors at sufficient temporal resolution to obtain the parameters that define off-axis crack initiation and growth. The availability of the high fidelity crack state quantification enables the benchmarking of existing damage models. Moreover the ACC methodology is a prerequisite for the development of improved off-axis crack evolution models. The automated experimental approach combined with the postprocessing methodology have therefore enabled the novel contributions described in the present paper as follows:

1. Investigation and quantification of the influence of VA block loading and change in R-ratio on the crack density evolution process in GFRP when compared to CA loading results.

2. Derivation of stochastic fatigue failure parameters for off-axis crack initiation and propagation in terms of Weibull distribution parameters along with the derivation of classical S-N and Paris’ Law relationships.

3. Comparison of the predicted stiffness degradation obtained from a micro-mechanical model utilising high fidelity off-axis crack evolution data with measured stiffness degradation and a ply discount approach.

\section{Material and Experiment}

Two laminated GFRP plates were produced using manual material placement and vacuum assisted resin transfer moulding. The glass fibre was $600 \mathrm{~g} / \mathrm{m}^{2}$ stitched E-glass NCF UD and a typical epoxy 
Glud, J.A., Dulieu-Barton, J.M., Thomsen, O.T. and Overgaard, L.C.T., "Fatigue damage evolution in GFRP laminates with constrained off-axis plies”, Composites Part A, http://dx.doi.org/10.1016/j.compositesa.2017.02.005

resin and hardener used in infusion processes comprised the matrix material. The layup of the laminates were $\left[0^{\circ}\right]_{6}$, i.e. UD and $\left[0^{\circ} /-60^{\circ} / 0^{\circ} / 60^{\circ}\right]_{s}$, i.e. MD. The single plies $\left(-60^{\circ}\right)$ and the double plies $\left(60^{\circ}\right)$ in the symmetric and balanced MD laminate will be referred to as the thin and the thick layer, respectively; the average ply thickness was $0.54 \mathrm{~mm}$. A microscopic examination of the thickness of the laminate layers revealed that the thick layer in average was 1.9 times thicker than the thin layer and not twice as thick as expected. This means that the average fibre volume fraction in the thick layer is higher than in the thin layer. An indication of the stitching pattern in the MD laminate that holds the fibres together prior to consolidation is given in the image shown in Figure 1(a). GFRP end-tabs were bonded to the laminated plates, and specimens were cut using water jet cutting to the dimensions given in Figure 1(b). The UD specimens were used to determine the elastic constants for the single ply, and the MD specimens were used to characterise the off-axis crack evolution. The specimen thickness and the derived elastic constants for both laminates are provided in Table 1 . Strip specimens were cut from $\left[0^{\circ}\right]_{6}$ material $150 \mathrm{~mm}$ long and $25 \mathrm{~mm}$ wide. These were tested to failure in uniaxial tension to provide the $E_{1}, E_{2}, v_{12}$ values given in Table 1. An upscaled version of the Modified Arcan Fixture [27] was used to obtain $\mathrm{G}_{12}$.

\begin{tabular}{|c|c|c|c|c|c|}
\hline \multicolumn{5}{|c|}{$\left[\mathrm{O}_{6}\right]$ Laminate } \\
\hline$E_{1}[\mathrm{GPa}]$ & $E_{2}[\mathrm{GPa}]$ & $\mathrm{V}_{12}$ & $\mathrm{G}_{12}[\mathrm{GPa}]$ & $\mathrm{V}_{\mathrm{f}}$ & Thickness $[\mathrm{mm}]$ \\
\hline $44.3 \pm 2.5$ & $12.1 \pm 0.23$ & $0.36 \pm 0.02$ & $3.93 \pm 0.09$ & $56 \%$ & $3.07 \pm 0.03$ \\
\hline \multicolumn{5}{|c|}{$[0 /-60 / 0 / 60]_{s}$ Laminate } \\
\hline & $E_{x 0}^{\text {lam }}[\mathrm{GPa}]$ & \multicolumn{3}{c|}{$\mathrm{V}_{\mathrm{f}}$} & Thickness $[\mathrm{mm}]$ \\
\hline & $27.0 \pm 0.2$ & $53 \%$ & $4.32 \pm 0.1$ \\
\hline
\end{tabular}

Table 1: Measured properties of UD and MD laminate.

The fibre volume fractions were measured by means of a burn-off test and are also reported in Table 1. The measured stiffness $\left(E_{x}\right)$ of the MD laminate given in Table 1 is in close agreement with the prediction of Classical Laminate Theory (CLT) at the initial reference state $(n=0)$. 
The ACC technique [26] was used for the crack state quantification and was facilitated using Transilluminated White Light Imaging (TWLI). The progressive stiffness degradation was evaluated using the strains obtained from both an extensometer and 2D lock-in DIC [28]. The set-up is shown in Figure 1(c). A 5 MPixel camera was used for both the DIC and TWLI measurements. The measurements were taken from different positions on the test specimens as shown in Figure 1(b). For the DIC a random speckle pattern was spray painted onto the specimen surface. A subset size of 121 by 121 pixels with an overlap of 60 pixels was used to compute the strain field. The strain amplitudes were computed by applying the lock-in DIC to 5 consecutive images, [28]. The full field strain measurements were then averaged over the entire region of interest as shown in Figure 1(b). For both the DIC and the extensometer readings the laminate Young's modulus (for coordinate system see Figure 1(b)) was computed as: $E_{x n}^{l a m}=\frac{\sigma_{x x}^{a}}{\epsilon_{x x}^{a}}$, where superscript $a$ denotes amplitude and $n$ denotes the cycle number. The fatigue tests were conducted in an Instron 8820 load frame with a $100 \mathrm{kN}$ servo-hydraulic actuator operated in load control. A requirement for the lockin DIC algorithm is that the loading frequency cannot be an integer multiple of the DIC sampling frequency. Consequently, the loading frequency was chosen to $5.2 \mathrm{~Hz}$. In total, 20 fatigue tests were carried out. A summary of the test parameters is given in Table 2. Linear elastic material properties are assumed throughout the remaining analyses. Hence, the stress state within the laminate is computed using CLT, and as the specimens are loaded in uniaxial tension the stress state is uniquely determined based on one stress component and the constitutive properties given in Table 1. 


\begin{tabular}{|c|c|c|c|c|c|c|c|c|}
\hline \multirow{2}{*}{$\begin{array}{l}\text { Test } \\
\text { Type }\end{array}$} & \multirow{2}{*}{$\begin{array}{c}\text { Maximum } \\
\text { transverse } \\
\text { normal stress in } \\
\text { off-axis layer } \\
\text { [MPa] }\end{array}$} & \multirow{2}{*}{$\begin{array}{c}F_{\text {mean }} \\
{[\mathrm{kN}]}\end{array}$} & \multirow{2}{*}{$\begin{array}{c}F_{a m p} \\
{[\mathrm{kN}]}\end{array}$} & \multirow{2}{*}{$R=\frac{F_{\text {max }}}{F_{\min }}$} & \multirow[t]{2}{*}{ Cycles } & \multirow{2}{*}{$\begin{array}{l}\text { No. } \\
\text { Tests }\end{array}$} & \multicolumn{2}{|c|}{$\begin{array}{l}\text { Sampling } \\
\text { [Frames per } \\
\text { second] }\end{array}$} \\
\hline & & & & & & & DIC & TWLI \\
\hline T-T CA & $\sigma_{22}^{\max }=69$ & 13.75 & 11.25 & 0.1 & $2 \cdot 10^{4}$ & 5 & $\begin{array}{c}0.125 \\
\text { or } 0.25\end{array}$ & $\begin{array}{c}0.125 \\
\text { or } 0.25 \\
\end{array}$ \\
\hline T-T CA & $\sigma_{22}^{\max }=50$ & 10 & 8.2 & 0.1 & $1.1 \cdot 10^{5}$ & 5 & $\begin{array}{c}0.25 \text { or } \\
1^{*}\end{array}$ & $\begin{array}{c}0.25 \text { or } \\
1 *\end{array}$ \\
\hline T-T CA & $\sigma_{22}^{\max }=39$ & 7.7 & 6.3 & 0.1 & $4.5 \cdot 10^{5}$ & 4 & 1* & 1* \\
\hline T-T CA & $\sigma_{22}^{\max }=31$ & 6.2 & 5 & 0.1 & $1.6 \cdot 10^{6}$ & 2 & N/A & $1 *$ \\
\hline C-T CA & $\sigma_{22}^{\max }=37$ & 5.2 & 8.2 & -0.2 & $10^{5}$ & 2 & N/A & $1^{*}$ \\
\hline T-T VA & $\sigma_{22}^{\max }=39 / 50$ & $\begin{array}{c}7.7 / \\
10\end{array}$ & $\begin{array}{c}8.2 / \\
6.3\end{array}$ & 0.1 & $3.5 \cdot 10^{5}$ & 2 & N/A & $1^{*}$ \\
\hline
\end{tabular}

* Discrete sampling to reduce data i.e. the DIC \& TWLI system only recorded at the stated frame rate in predefined timeslots

Table 2: Definition of test series carried out.

The VA tests consisted of a block of $10^{5}$ cycles at a stress level of $\sigma_{22}^{\max }=39 \mathrm{MPa}$ followed by a block of $\sim 2.5 \cdot 10^{5}$ cycles at $\sigma_{22}^{\max }=50 \mathrm{MPa}$. The image filtering parameters required for using ACC were chosen based on the procedure described in [26] and the Gabor parameters $\left(\gamma, \sigma_{G}\right.$ and $\left.\lambda\right)$ along with the spatial resolution of the test setup are given in Table 3.

\begin{tabular}{|c|c|c|c|c|c|}
\hline Layer & $\boldsymbol{\theta}\left[^{\circ}\right]$ & $\boldsymbol{\gamma}$ & $\begin{array}{c}\boldsymbol{\sigma}_{\boldsymbol{G}} \\
{[\text { Pixel] }}\end{array}$ & $\begin{array}{c}\lambda \\
{[\text { Pixel] }]}\end{array}$ & $\begin{array}{c}\text { Spatial } \\
\text { Resolution } \\
{[\boldsymbol{\mu m} / \boldsymbol{p i x \boldsymbol { x }}]}\end{array}$ \\
\hline Thin & -60 & 0.14 & 7 & 16 & 18.4 \\
\hline Thick & 60 & 0.14 & 8 & 22 & 18.4 \\
\hline
\end{tabular}

Table 3: Image filtering parameters used in ACC and spatial resolution for TWLI.

\section{Crack Density Evolution \& Stiffness Degradation}

The damage evolution observed in all the fatigue tests was identical. The first damage mode was initiation of off-axis cracks, mainly at the specimen edges, which grew across the specimen until they were arrested by meeting another crack or the opposite edge. The reason for this behaviour could potentially result from damage introduced by the water jet cutting process. However, it should 
be noted that cracks initiating from the edges of polished specimens has been reported in [9] for a similar layup, and it is therefore considered that the behaviour is due to free edge effects and not manufacturing induced defects.

A commonly used way of compressing the crack state is to compute the average crack density in the measuring volume $[2-4,8,9,18,23,24]$. The crack density definition used for all the reported crack density measurements is given by:

$$
\rho=\frac{\sum_{i=1}^{n} L_{c r a c k}^{i}}{A}
$$

where $L_{\text {crack }}^{i}$ is the length of the $\mathrm{i}^{\text {th }}$ crack, and $A$ is the area of the measuring volume which is illustrated on Figure 1(b) with a red dashed box.

The crack densities derived from the fatigue tests for the thin and thick layer for the T-T CA tests are shown in Figure 2. The results are consistent with the results reported in [9]. According to the idea of a Characteristic Damage State (CDS) [29], there can only be one saturation value for a particular layer. However, as seen in Figure 2, the slopes of the curves flatten, i.e. saturate, at a different stress levels, even though a clear asymptotic saturation is not achieved. Therefore the saturation value for each stress level is referred to throughout the remainder of the paper as the 'apparent saturation value'. Figure 2 shows that the crack density evolution rate and apparent saturation value increase as the fatigue stress is increased. Furthermore, the crack density observed for the thick layer is lower than the crack density observed for the thin layer. This is because when an off-axis crack is present within an off-axis ply, the stress in the off-axis ply is decreased in the neighbourhood of the crack, which is recovered by shear lag. A lower stress level generally impedes new crack formation and consequently if the layer thickness is increased the crack density will decrease as the distance required for stress recovery increases. The variation in crack densities between specimens subjected to the same loading conditions can be attributed to the inherent 
Glud, J.A., Dulieu-Barton, J.M., Thomsen, O.T. and Overgaard, L.C.T., "Fatigue damage evolution in GFRP laminates with constrained off-axis plies”, Composites Part A, http://dx.doi.org/10.1016/j.compositesa.2017.02.005

material variability and not human errors in the counting process, since ACC has been used for all the tests.

The stiffness degradation measured for the T-T CA tests is plotted in Figure 3, where it is clear that as the load is increased the stiffness degradation occurs more rapidly. As more damage is induced in the material, the crack density evolution rate increases along with the apparent saturation values. Slipping of the extensometer occurred for some of the tests, and these were removed from the analysis. It is seen that lock-in DIC and extensometer readings show good agreement for the 50 MPa and 39 MPa stress levels. The lock-in DIC results were omitted for the $69 \mathrm{MPa}$ stress level, as the damage development and hence the stiffness degradation changed significantly during the 104 cycles necessary to collect the image data for the lock-in DIC thereby rendering measurements unreliable.

Crack density measurements from the VA T-T block loading tests can be found in Figure 4 along with CA 50 MPa stress level T-T measurements for easy comparison (both $R=0.1$ ). The results of the CA 50 MPa tests have been shifted $9 \times 10^{4}$ cycles so that the average crack densities of the VA and CA tests are the same at $10^{5}$ cycles, where the load in the VA test was increased from $39 \mathrm{MPa}$ to $50 \mathrm{MPa}$. It is observed that the crack density evolution rate appears to be identical for the two test series when the load is increased. To the authors knowledge this is the only available experimental study of off-axis crack density evolution for GFRP under VA block loading in the open literature. Crack density evolution results in CFRP subjected to VA block loading can be found in refs. [3032], where [32] measures the crack density indirectly by measuring the stiffness degradation. The key finding of the VA block loading study is that the crack density in GFRP is a suitable damage measurement variable for defining load-history dependent effects for a low-high sequence of VA block loading. 
Glud, J.A., Dulieu-Barton, J.M., Thomsen, O.T. and Overgaard, L.C.T., "Fatigue damage evolution in GFRP laminates with constrained off-axis plies”, Composites Part A, http://dx.doi.org/10.1016/j.compositesa.2017.02.005

As for VA T-T block loading, only scarce experimental results on the influence of the load ratio on the off-axis crack density evolution in GFRP can be found in literature. The only available study on this matter for GFRP is the recent publication in [33] that investigated prepreg, whereas [31] reports crack density evolution for quasi-isotropic CFRP laminates subjected to different load ratios. The results published in [33] does not include off-axis crack density evolution results, but only number of cycles to first crack initiation and subsequent crack growth rates. Therefore, in this work the influence of decreasing the load ratio on the crack density evolution in GFRP is investigated. Two C-T CA tests were carried out at a stress level of $37 \mathrm{MPa}$ and with $\mathrm{R}=-0.2$ with the aim of comparing to the results observed in the T-T CA tests. It is important to note that the load amplitude in the $37 \mathrm{MPa}$ C-T CA tests is equal to the load amplitude in the $50 \mathrm{MPa}$ T-T CA tests. At the load ratio $\mathrm{R}=-0.2$ all stress components in the $37 \mathrm{MPa} \mathrm{C}-\mathrm{T}$ CA tests attain a slightly lower value than the stress values in the $39 \mathrm{MPa}$ T-T CA test. In Figure 5 the measured crack densities for the $37 \mathrm{MPa}$ C-T CA tests are plotted along with the T-T fatigue results obtained for stress levels of $39 \mathrm{MPa}$ and $50 \mathrm{MPa}$. The crack density evolution rates and apparent saturation values for the $37 \mathrm{MPa}$ C-T CA tests are higher than for the $39 \mathrm{MPa}$ T-T CA tests and significantly lower than for the $50 \mathrm{MPa}$ T-T CA tests. From the crack density evolution results it is clear that T-T loading induces more damage in the material compared to C-T loading when the load amplitudes for the two test configurations are the same. This can be attributed to the crack surfaces closing in the compressive part of the load cycle and thereby reducing the damaging effect of the applied load. However, as shown in Figure 5, the damage is significantly greater in the $37 \mathrm{MPa}$-T CA tests than in the $39 \mathrm{MPa}$ T-T CA tests, despite the fact that the maximum stress is lower in the $37 \mathrm{MPa}$ C-T CA tests. This result confirms that the influence of load ratio reported in [33] also holds true for GFRP laminates made from NCF, because the higher crack density evolution rates and apparent saturation values for the $37 \mathrm{MPa} C-\mathrm{T}$ tests, as compared to the $39 \mathrm{MPa}$ T-T tests, are the direct result of cracks initiating earlier and 
Glud, J.A., Dulieu-Barton, J.M., Thomsen, O.T. and Overgaard, L.C.T., "Fatigue damage evolution in GFRP laminates with constrained off-axis plies”, Composites Part A, http://dx.doi.org/10.1016/j.compositesa.2017.02.005

propagating faster. Further on, it should be noted that this type of behaviour is the same as reported for CFRP in [31].

Studying the entire crack density evolution up to the apparent saturation value reveals that if the amplitude is kept constant T-T loading is more damaging than C-T loading. However, it is also evident that the compressive part of the load cycle must have a damaging effect because the C-T test shows significantly more damage than the T-T $39 \mathrm{MPa}$ even though the maximum stress in the T-T 39 MPa test is higher and the amplitude of the tensile loading is similar for the two tests.

\section{Crack Initiation}

The crack density evolution study benefits from removing the potentially biased results obtained using manual counting, but it should also be noted that the increased temporal resolution and data rich nature of the current approach play an important role in defining accurate crack initiation and growth data. The number of cycles to initiation of the first observed off-axis crack in fatigue have been reported by numerous investigations, e.g. [2, 3, 9, 18], with the purpose of establishing an S-N curve to describe the relationship between the stress and the number of cycles required to initiate the first crack. However, the temporal resolution of the measurements is not provided, which may influence the derived results. Furthermore, there is no obvious physical reason why an S-N curve for a particular composite material should be derived based on the first crack initiation and not the subsequent cracks. Off-axis cracks represent localised damage, and if the cracks are sufficiently far apart, the development of subsequent cracks will represent independent damage events. Therefore, a method to determine if off-axis cracks are interacting with neighbouring cracks were proposed in [9], which used Finite Element (FE) modelling and Linear Elastic Fracture Mechanics (LEFM) to define a minimum distance between cracks where no interaction was found to occur. However, the method in [9] was not used to its full extent for crack initiation since only the first few initiating offaxis cracks were detected, so potentially important information about the stochastic nature of these 
Glud, J.A., Dulieu-Barton, J.M., Thomsen, O.T. and Overgaard, L.C.T., "Fatigue damage evolution in GFRP laminates with constrained off-axis plies”, Composites Part A, http://dx.doi.org/10.1016/j.compositesa.2017.02.005

phenomena was neglected. Therefore the present analysis does not only detect and measure the first few non-interacting cracks, but also the consecutive evolution up to the point where no more noninteracting cracks can be detected.

To investigate if the formation of new cracks can be regarded as independent from other existing cracks an FE based linear fracture mechanics unit-cell analysis similar to that found in [9] was carried out using ANSYS 15.0. A schematic of the unit-cell model is shown in Figure 6(a) and cracks were only modelled in one layer at a time for all analyses. The interaction between the layers is assumed to be negligible due to the $0^{\circ}$ UD layer separating the cracked layers. The Energy Release Rate (ERR) of an off-axis crack front will in general be a function of the crack length $L_{c}$ and crack spacing $L_{\rho}$, i.e. $E R R=f\left(L_{c}, L_{\rho}\right)$, due to 3D effects and the aforementioned shielding effect. If $L_{c}$ is sufficiently long, the influence of initial flaw geometry and crack front shape on the ERR become negligible and the ERR reaches a steady state value, which results in steady state crack growth [34]. If $L_{\rho}$ is sufficiently large the crack will not feel the presence of other cracks and can therefore be regarded as an isolated crack. Four FE analyses were carried out to study when the steady state ERR is reached and when cracks can be regarded as isolated. Two analyses studied how the mode I and mode II ERR in a single isolated crack embedded in either the thick or thin layers changed as $L_{c}$ increased. Two subsequent analyses studied how the ERR changed as $L_{\rho}$ was varied. The results of these parametric studies are shown in Figure 6(b) for the mode I ERR and in Figure 6(c) for the mode II ERR, and it is seen that when $L_{c}=L_{\rho}=4 t$ for both layers the mode I and mode II ERR reaches a steady state value. Based on the four analyses it is concluded, that an initiating crack is isolated from other cracks when $L_{\rho} \geq 4 t$ and is growing in a steady state manner as long as: $L_{c} \geq 4 t \wedge L_{\rho} \geq 4 t$. It should be noted that the definition of an isolated crack and steady state growth depends strongly on the constraining effect of adjacent layers, so the analysis presented here is not universal but specific to the laminate stacking sequence and ply thickness. 
To identify the crack initiation point a data mining process was carried out on all the ACC data collected for the four different T-T CA stress levels. The data mining was informed by the findings of the unit-cell fracture mechanics FE analysis so that an independent crack was defined to be located at least four times the layer thickness from a neighbouring crack. The results are shown in an S-N diagram in Figure 7. It should be noted that for the 69 MPa T-T CA test case many off-axis cracks initiated due to static overloading when the load was ramped up to the maximum amplitude, hence this explains the apparent low level of scatter in the data. The data points for $69 \mathrm{MPa}$ therefore represent the strongest initiation sites in the tested laminates. A high degree of scatter is seen in the data, where the number of cycles required to initiate an isolated crack vary over two orders of magnitude. The high scatter furthermore indicates that the physics of crack initiation is stochastic by nature, so the strength is best represented as a distribution of values rather than as one specific value. Therefore, a proper probability function must be identified to model the stochastic crack initiation in a meaningful way.

The residual strength degradation approach proposed for ultimate laminate failure [33, 34] assumes a direct relationship between static strength distribution, residual strength distribution and the distribution of number of cycles to failure, where the distribution is modelled using the Weibull distribution with a constant shape parameter. However, in [38] it was found that in fatigue, the shape parameter of the Weibull distribution may change when the constant amplitude fatigue load was decreased, due to a change in damage mode of the tested laminate. For the case of off-axis crack initiation [39] showed that the quasi-static strength distribution could be modelled by a twoparameter Weibull distribution. These results have facilitated the development of quasi-static crack evolution models as e.g. [40-42] based on the Weibull distribution. However, in terms of fatigue loading the stochastics of constrained off-axis crack initiation has not been quantified. In the 
following the Weibull parameters are derived so that the stochastic nature of fatigue damage accumulation is included.

The 2-parameter Weibull Cumulative Distribution Function (CDF) is given as follows:

$$
F(x)=1-\exp \left[-\left(\frac{x}{\eta}\right)^{\beta}\right] ; x>0
$$

where $\eta$ is known as the scale parameter and has same units as $x, \beta$ is usually referred to as the shape parameter, and $x$ is the stochastic variable with the unit of number of cycles [43]. The Weibull CDF can be linearized by taking the logarithm of Equation (2) twice:

$$
\begin{gathered}
-\ln (1-F(x))=\left(\frac{x}{\eta}\right)^{\beta} \Leftrightarrow \\
\ln (-\ln (1-F(x)))=\beta \ln (x)-\beta \ln (\eta)
\end{gathered}
$$

This linearization may be used to visually assess the fit in a Weibull probability plot. Thus, the relationship between the left hand side of Equation (3), $\ln (-\ln (1-F(x)))$, and the logarithmic number of cycles to failure $\ln (x)=\ln \left(N_{f}\right)$, should follow a linear trend for the Weibull distribution to model the crack initiation phenomenon. In Figure 8 the crack initiation data from Figure 7 is plotted in a Weibull probability plot. A linear trend in the dataset for both layers is clearly observed, and it is concluded that the Weibull distribution describes well the stochastic nature of the off-axis crack initiation.

Furthermore, it is seen in Figure 8 that the slope and hence shape parameter seems to be independent of the stress level. The Maximum Likelihood Estimate (MLE) of the shape parameter as well as the $0.05 \%$ and $95 \%$ confidence intervals on the estimated parameters is shown in Figure 9(a). The estimated shape parameters for all layers are close to being constant for the different stress levels with a maximum deviation of $12 \%$ to the shape parameter value averaged for all tests. Hence, 
it is not statistical significant to conclude that the shape parameter varies with the applied stress level or with the thickness of the layer. The confidence bounds for the estimated shape parameter values for the thick layer are rather wide. The reason for the wide confidence bounds is the lower crack density observed in the thick layer, and hence fewer data points. The shape parameter can be interpreted as a measure of the physical flaws in the material, whether it is inherent to the material itself or stems from the production processes used during manufacturing. In general terms, if the value of the shape parameter is low there is a high degree of variance and therefore the inherent flaws are unevenly distributed and of uneven severity in terms of damaging effect, whereas for a high value of the shape parameter the flaws are distributed uniformly and are causing more homogeneous damage. In essence, this means that the shape parameter cannot be considered as a material constant but rather as a measure of the uniformity of the processing flaws in the laminated composites. However, it is important to note that since the shape parameter is independent of stress level, the failure mode phenomenology on the microscopic level is independent of the stress level. The conclusion is that it was reasonable to assume a constant shape parameter as in [20-22], when modelling constrained off-axis crack initiation in fatigue, thus clearing an important point for future studies.

The quantiles of the Weibull CDF are found by solving Equation (2) for $x$ and setting $F(x)=p$, where $p$ denotes a general percentile. This gives:

$$
x=\left[\ln \left(\frac{1}{1-p}\right)\right]^{1 / \beta} \cdot \eta
$$

For the case where $p=1-1 / e=0.632$, then $x=\eta$ irrespective of the value of $\beta$. This is the reason why $\eta$ is often referred to as the characteristic life. Since $\eta$ is derived based on all independent initiated cracks in the measuring volume it is expected to be a more robust and accurate measure for deriving the material S-N curve as compared to the case of using the first crack 
initiation results as done in $[2,3,9,18]$. Figure 9(b) shows the characteristic life plotted in the form of applied stress vs. the Weibull scale parameter and fitted with an S-N power-law of the type $S=S_{0} N^{k}$. The power-law model provides an adequate fit to the characteristic life. Therefore the probability of off-axis crack initiation at a given number of cycles can be determined by combining the derived power law with (2) as

$$
P_{S}(x, S)=1-\exp \left(-\left[\frac{x}{\left(\frac{S}{S_{0}}\right)^{1 / k}}\right]^{\beta}\right)
$$

where the 3 empirical constants, $S_{0}, k$ and $\beta$ can be efficiently determined by data mining the crack field data and derived values for these constants are given in Table 4.

Therefore, it has been shown that a two-parameter Weibull distribution is an effective means of modelling the stochastic of off-axis crack initiation. Furthermore, it has been shown that the shape parameter of the Weibull distribution does not change with stress level and does not change between the tested ply thicknesses.

\section{Crack Growth Rate (CGR)}

It was demonstrated in [9] that isolated cracks grow in a stable manner with a growth rate defined by a Paris’ law like relationship. To capture the CGR, the ACC methodology [26] is extended so that isolated cracks are tracked and their length recorded. To determine if a tracked crack could be considered to isolated, a radius of 4 times the layer thickness from the crack-tip was searched for the existence of neighbouring cracks. For as long as no neighbouring cracks were present in the search radius and the crack was longer than 4 times the layer thickness $\left(L_{c} \geq 4 t\right)$, the cycles versus change in crack length for each processed image was saved. Only cracks initiating from the edges were used for determining the CGR, because in general these cracks initiated first and only have one crack front which made the associated data collection simpler. The results from the T-T CA test 
at $69 \mathrm{MPa}$ were disregarded since the temporal resolution was not sufficiently high to obtain isolated CGR. The change in crack lengths as function of number of cycles for the detected isolated cracks are plotted in Figure 10(a) and these crack growth curves were fitted with a linear model using an MLE to determine the crack growth rate. The CGR results are plotted against the computed ERR for an isolated crack front in Figure 10(b). A large variance in the data is observed, and the magnitude of the variance is seen to be approximately the same as found in [25]. The large degree of scatter in the dataset indicates that a single Paris' Law relationship is not sufficient to describe the physics of crack propagation.

In the same way as for initiation, a statistical analysis of the distribution of crack growth rates was carried out. However, only the results from the thin layer included enough data points to study the statistical nature of the distribution. The CGR data for the thin layer is shown in a Weibull probability plot in Figure 10(c). A linear trend in the dataset is clearly observed for all stress levels, and it is concluded that the Weibull distribution effectively describes the stochastic nature of the off-axis crack propagation process. Furthermore, it is seen in Figure 10(c) that the slope and hence shape parameter seem to be independent of the strain energy release rate level. Based on further statistical analysis of the determined shape parameter for crack propagation it was found that it is not statistical significant to conclude that the shape parameter varies with the strain energy release rate level.

To model the influence of the ERR on the CGR the determined scale parameters for each ERR level were fitted with a typical power law expression in the form of a Paris’ law like relationship, i.e. $C G R=D \cdot G_{t o t}{ }^{n}$. The estimated parameters for the thick and thin layers are given in Table 4. The fitted Paris’ Law relationships are plotted in Figure 10(b), which shows that the Paris’ Law relationship provides a good model of the influence of ERR on the CGR. This means that a suitable 
way of modelling the crack growth field is to combine the Weibull distribution with the Paris' Law relationship as follows:

$$
P_{C}\left(C G R, G_{t o t}\right)=1-\exp \left(-\left[\frac{C G R}{D \cdot G_{\text {tot }}}\right]^{\beta_{c}}\right)
$$

The $10^{\text {th }}$ and $90^{\text {th }}$ percentile curves obtained by using Equation (6) for the crack growth field in the thin layer are shown with dashed lines in Figure 10(b), which, as expected, contain the majority of measured crack growth rates.

\begin{tabular}{|c|c|c|c|c|c|c|}
\cline { 2 - 7 } \multicolumn{1}{c|}{} & \multicolumn{3}{c|}{ Crack initiation } & \multicolumn{3}{c|}{ Crack growth } \\
\hline Layer & $\boldsymbol{S}_{\mathbf{0}}[\mathrm{MPa}]$ & $\boldsymbol{k}$ & $\beta$ & $\log (\boldsymbol{D})$ & $\boldsymbol{n}$ & $\beta_{c}$ \\
\hline Thick & 103 & -0.10 & 1.33 & 1.14 & 4.37 & 1.25 \\
\hline Thin & 105 & -0.11 & 1.36 & 2.08 & 4.68 & - \\
\hline
\end{tabular}

Table 4: Measured S-N and Paris' law parameters. For Paris' law the units for $G_{\text {tot }}$ is in $\left[\mathrm{kJ} / \mathrm{m}^{2}\right]$ and CGR is in $[\mathrm{mm} /$ cycle $]$.

A consistent measurement of isolated crack growth has provided results showing the wide scatter in crack propagation rates and that this scatter and the stochastic nature of crack growth is accurately modelled by a Weibull distribution with a shape parameter which is independent of ERR level.

\section{Benchmark of Stiffness Degradation Models}

A common way to model the performance of a damaged laminate in progressive continuum damage models is to use a ply discount type method [13-17]. A sudden ply discount method adopted in [13] is used when failure is predicted within a ply, and a gradual degradation is used up until failure. The sudden degradation rule adopted by [13] prescribes $E_{2}, G_{12}$, and $v_{12}$ to be set to zero, when first ply "matrix tension and shear" failure occurs. However, a sudden discount method does not describe the gradual degradation process occurring after the first crack has initiated (i.e. first ply failure) as observed in the present paper as well as in several studies [2-4, 6, 8, 9, 18]. To benchmark the 
degradation predicted by [13] after first ply failure against a micro-mechanical model, the crackface-displacement model known as 'GLOB-LOC' was adopted [44] and implemented using CLT to compare with the experimentally obtained stiffness degradation (i.e. with the extensometer and the DIC). Here the crack density measurements derived from the ACC are used as inputs for the GLOB-LOC model as the GLOB-LOC model does not provide means of predicting the crack density evolution. A comparison is provided in Figure 11 of the different approaches which shows very good agreement between the GLOB-LOC model predictions and the experimental data, whereas the sudden ply discount method from [13] is overly conservative. The GLOB-LOC has previously been benchmarked against crack density measurements obtained from edge examination [45], where the authors found the GLOB-LOC to overestimate the stiffness of the laminate. However, it is clear that based on the present benchmark, where the GLOB-LOC is informed with crack density data obtained from ACC, it can be concluded that GLOB-LOC effectively predicts the mechanical performance of the tested laminate with a small underestimation of the laminate stiffness at high crack densities.

\section{Conclusions}

A novel high temporal resolution and data-rich characterisation of off-axis crack evolution in GFRP laminates has been presented. The characterisation is enabled by a fully automated crack identification and counting procedure, known as the Automatic Crack Counting methodology (ACC) presented in [26]. The high temporal resolution and data-rich characterisation has allowed for the following conclusions to be made:

1. Crack initiation and crack growth can be studied in greater detail than manual counting because the ACC approach for the first time makes it feasible to detect and measure the crack evolution process throughout the entire fatigue test with sufficient temporal resolution. 
2. The crack density is a suitable damage measure for GFRP subjected to a low-high sequence of variable amplitude block loading, and T-T loading results in a higher crack density evolution rate and apparent saturation value than C-T loading for the same load amplitude in GFRP.

3. It is possible to efficiently derive the classical S-N relationship and Paris’ Law like curves from the data obtained using the ACC approach only taking into account non-interacting cracks. Thus the nature and magnitude of the stress is established at every measurement point throughout the fatigue test providing an enhanced understanding of the causes of the damage progression.

4. The Weibull distribution models effectively the stochastic nature of isolated off-axis crack initiation and crack growth rate, and the Weibull parameters are derived directly, i.e. without resorting to inverse techniques, using ACC due to the data rich nature of the measurement method.

5. The shape parameter of the Weibull distribution is independent of the applied stress and does not vary with ply thicknesses.

6. The GLOB-LOC model slightly under predicts the stiffness of the degraded laminate whereas the sudden ply discount policy under predicts the stiffness by a large margin indicating that the approach is not suitable for modelling fatigue damage.

Thus considering the large number of variables that influence the fatigue damage evolution and the stochastic nature of the material, it is clear that the data rich characterisation method using ACC has proved very effective in providing a more detailed knowledge of the fatigue evolution process. In the future, as the method is not specific to the laminate layup used in the paper, it is expected the approach described here will be employed to cover other factors that influence fatigue damage evolution in laminated composite materials such as different multiaxial stress states, stacking sequence and manufacturing processes. 
Glud, J.A., Dulieu-Barton, J.M., Thomsen, O.T. and Overgaard, L.C.T., "Fatigue damage evolution in GFRP laminates with constrained off-axis plies”, Composites Part A, http://dx.doi.org/10.1016/j.compositesa.2017.02.005

\section{Acknowledgements}

The work presented was conducted as a part of a Ph.D. project at the Department of Mechanical and Manufacturing Engineering, Aalborg University, Denmark. A part of the research was carried out during a visit of the corresponding author at the University of Southampton, Faculty of Engineering and the Environment, Southampton, UK. The project has received sponsorship from Innovation Fund Denmark through the "Danish Centre for Composite Structures and Materials for Wind Turbines (DCCSM)”. The support received is gratefully acknowledged.

\section{References}

[1] Jamison, Russell D. Characterization and analysis of damage mechanisms in tension-tension fatigue of graphite/epoxy laminates. vol. 1. ASTM International; 1984.

[2] Tong J, Guild FJ, Ogin SL, Smith PA. On matrix crack growth in quasi-isotropic laminates I. Experimental investigation. Compos Sci Technol 1997;57:1527-35. doi:10.1016/s02663538(97)00080-8.

[3] Wharmby AW, Ellyin F. Damage growth in constrained angle-ply laminates under cyclic loading. Compos Sci Technol 2002;62:1239-47. doi:10.1016/s0266-3538(02)00075-1.

[4] Adden S, Horst P. Stiffness degradation under fatigue in multiaxially loaded non-crimpedfabrics. Int J Fatigue 2010;32:108-22. doi:10.1016/j.ijfatigue.2009.02.002.

[5] van Leeuwen H, van Delft D, Heijdra J, Braam H, Jørgensen ER, Lekou D, et al. Comparing fatigue strength from full scale blade tests with coupon-based predictions. J Sol Energy Eng 2002;124:404. doi:10.1115/1.1509463.

[6] Wharmby A. Observations on damage development in fibre reinforced polymer laminates under cyclic loading. Int J Fatigue 2003;25:437-46. doi:10.1016/s0142-1123(02)00118-4.

[7] Zangenberg J, Brondsted P, Gillespie JW. Fatigue damage propagation in unidirectional glass fibre reinforced composites made of a non-crimp fabric. J Compos Mater 2013;48:2711-27. doi:10.1177/0021998313502062.

[8] Tong J, Guild FJ, Ogin SL, Smith PA. Off-axis fatigue crack growth and the associated energy release rate in composite laminates. Appl Compos Mater 1997;4:349-59. doi:10.1007/BF02481399.

[9] Quaresimin M, Carraro PA, Mikkelsen LP, Lucato N, Vivian L, Brøndsted P, et al. Damage evolution under cyclic multiaxial stress state: A comparative analysis between glass/epoxy laminates and tubes. Compos Part B Eng 2014;61:282-90. doi:10.1016/j.compositesb.2014.01.056.

[10] Hashin Z, Rotem A. A fatigue failure criterion for fiber reinforced materials. J Compos Mater 1973;7:448-64. doi:10.1177/002199837300700404.

[11] Nijssen R. Optidat - database reference document. Kluisgat 51771 MV Wieringerwerf, the Netherlands: 2006. 
[12] Quaresimin M, Susmel L, Talreja R. Fatigue behaviour and life assessment of composite laminates under multiaxial loadings. Int J Fatigue 2010;32:2-16.

doi:10.1016/j.ijfatigue.2009.02.012.

[13] Shokrieh MM, Lessard LB. Progressive fatigue damage modeling of composite materials, Part I: Modeling. J Compos Mater 2000;34:1056-80. doi:10.1177/002199830003401301.

[14] Passipoularidis VA, Philippidis TP, Brondsted P. Fatigue life prediction in composites using progressive damage modelling under block and spectrum loading. Int J Fatigue 2011;33:13244. doi:10.1016/j.ijfatigue.2010.07.011.

[15] Eliopoulos EN, Philippidis TP. A progressive damage simulation algorithm for GFRP composites under cyclic loading. Part I: Material constitutive model. Compos Sci Technol 2011;71:742-9. doi:10.1016/j.compscitech.2011.01.023.

[16] Kennedy CR, Brádaigh CMÓ, Leen SB. A multiaxial fatigue damage model for fibre reinforced polymer composites. Compos Struct 2013;106:201-10.

doi:10.1016/j.compstruct.2013.05.024.

[17] Sun XS, Haris A, Tan VBC, Tay TE, Narasimalu S, Della CN. A multi-axial fatigue model for fiber-reinforced composite laminates based on Puck's criterion. J Compos Mater 2012;46:449-69. doi:10.1177/0021998311418701.

[18] Quaresimin M, Carraro PA. Damage initiation and evolution in glass/epoxy tubes subjected to combined tension-torsion fatigue loading. Int J Fatigue 2014;63:25-35. doi:10.1016/j.ijfatigue.2014.01.002.

[19] Carraro PA, Quaresimin M. A stiffness degradation model for cracked multidirectional laminates with cracks in multiple layers. Int J Solids Struct 2015;58:34-51. doi:10.1016/j.ijsolstr.2014.12.016.

[20] Carraro PA. Multiaxial fatigue behaviour of composite materials: characterisation and modelling. PhD dissertation. University of Padova, 2014.

[21] Kahla H Ben, Varna J, Pupurs A. Microcracking in layers of composite laminates in cyclic loading with tensile transverse stress component in layers. 20th Int. Conf. Compos. Mater., 2015.

[22] Huang Y. Stochastic damage evolution under static and fatigue loading in composites with manufacturing defects. PhD dissertation. Texas A\&M University, 2012.

[23] Adden S, Horst P. Damage propagation in non-crimp fabrics under bi-axial static and fatigue loading. Compos Sci Technol 2006;66:626-33. doi:10.1016/j.compscitech.2005.07.034.

[24] Li C, Ellyin F, Wharmby A. On matrix crack saturation in composite laminates. Compos Part B Eng 2003;34:473-80. doi:10.1016/S1359-8368(03)00020-9.

[25] Boniface L, Ogin SL. Application of the paris equation to the fatigue growth of transverse ply cracks. J Compos Mater 1989;23:735-54. doi:10.1177/002199838902300706.

[26] Glud JA, Dulieu-Barton JM, Thomsen OT, Overgaard LCT. Automated counting of off-axis tunnelling cracks using digital image processing. Compos Sci Technol 2016;125:80-9. doi:10.1016/j.compscitech.2016.01.019.

[27] Taher ST, Thomsen OT, Dulieu-Barton JM, Zhang S. Determination of mechanical properties of PVC foam using a modified Arcan fixture. Compos Part A Appl Sci Manuf 
2012;43:1698-708. doi:10.1016/j.compositesa.2011.11.010.

[28] Fruehmann RK, Dulieu-Barton JM, Quinn S, Tyler JP. The use of a lock-in amplifier to apply digital image correlation to cyclically loaded components. Opt Lasers Eng 2015;68:149-59. doi:10.1016/j.optlaseng.2014.12.021.

[29] Reifsnider KL. Damage in composite materials: basic mechanisms, accumulation, tolerance, and characterization. ASTM; 1982. doi:10.1520/STP775-EB.

[30] Ogi K, Yashiro S, Niimi K. A probabilistic approach for transverse crack evolution in a composite laminate under variable amplitude cyclic loading. Compos Part A Appl Sci Manuf 2010;41:383-90. doi:10.1016/j.compositesa.2009.11.005.

[31] Bartley-Cho J, Gyu Lim S, Hahn HT, Shyprykevich P. Damage accumulation in quasiisotropic graphite/epoxy laminates under constant-amplitude fatigue and block loading. Compos Sci Technol 1998;58:1535-47. doi:10.1016/S0266-3538(97)00214-5.

[32] Plumtree A, Melo M, Dahl J. Damage evolution in a [ \pm 45$] 2 S$ CFRP laminate under block loading conditions. Int J Fatigue 2010;32:139-45. doi:10.1016/j.ijfatigue.2009.02.020.

[33] Quaresimin M, Carraro PA, Maragoni L. Influence of load ratio on the biaxial fatigue behaviour and damage evolution in glass/epoxy tubes under tension-torsion loading. Compos Part A Appl Sci Manuf 2015;78:294-302. doi:10.1016/j.compositesa.2015.08.009.

[34] Ho S, Suo Z. Tunneling cracks in constrained layers. J Appl Mech 1993;60:890. doi:10.1115/1.2900998.

[35] Garrett KW, Bailey JE. Multiple transverse fracture in 90 cross-ply laminates of a glass fibrereinforced polyester. J Mater Sci 1977;12:157-68. doi:10.1007/BF00738481.

[36] Yang JN, Liu MD. Residual strength degradation model and theory of periodic proof tests for graphite/epoxy laminates. J Compos Mater 1977;11:176-203. doi:10.1177/002199837701100205.

[37] Hahn HT, Kim RY. Proof testing of composite materials. J Compos Mater 1975;9:297-311. doi:10.1177/002199837500900308.

[38] Hahn HT, Kim RY. Fatigue behavior of composite laminate. J Compos Mater 1976;10:15680. doi:10.1177/002199837601000205.

[39] Manders PW, Chou T-W, Jones FR, Rock JW. Statistical analysis of multiple fracture in 0/90/0 glass fibre/epoxy resin laminates. J Mater Sci 1983;18:2876-89. doi:10.1007/BF00700768.

[40] Wang ASD, Chou PC, Lei SC. A stochastic model for the growth of matrix cracks in composite laminates. J Compos Mater 1984;18:239-54. doi:10.1177/002199838401800304.

[41] Takeda N, Ogihara S. In situ observation and probabilistic prediction of microscopic failure processes in CFRP cross-ply laminates. Compos Sci Technol 1994;52:183-95. doi:10.1016/0266-3538(94)90204-6.

[42] Vinogradov V, Hashin Z. Probabilistic energy based model for prediction of transverse cracking in cross-ply laminates. Int J Solids Struct 2005;42:365-92. doi:10.1016/j.ijsolstr.2004.06.043.

[43] John I. McCool. Using the weibull distribution: reliability, modeling and inference. First 
Edit. John Wiley \& Sons, Inc; 2012.

[44] Varna J. Modelling mechanical performance of damaged laminates. J Compos Mater 2013;47:2443-74. doi:10.1177/0021998312469241.

[45] Sisodia S, Gamstedt EK, Edgren F, Varna J. Effects of voids on quasi-static and tension fatigue behaviour of carbon-fibre composite laminates. J Compos Mater 2015;49:2137-48. doi:10.1177/0021998314541993.

(a) Stitching

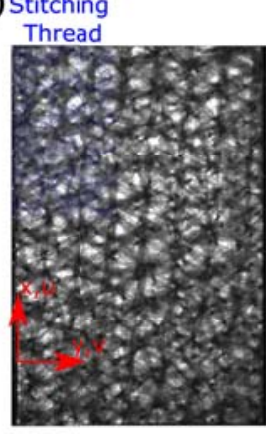

(b)

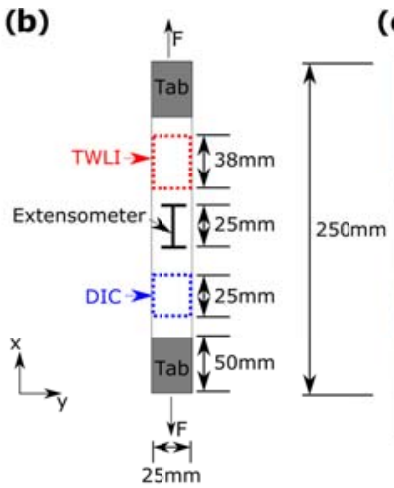

(c)

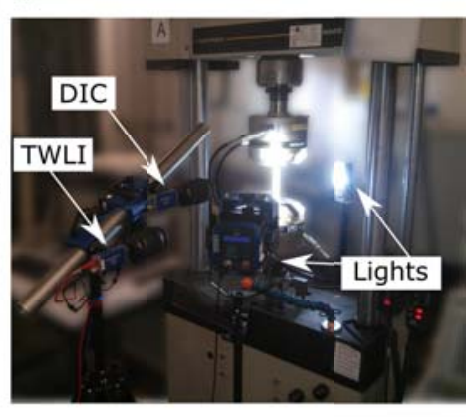

Figure 1: (a) stitching pattern in the MD laminate as seen by camera (b) Specimen

configuration/dimensions and measurement volume for Lock-in DIC, extensometer and

TWLI. (c) Experimental setup for TWLI and Lock-in DIC. 


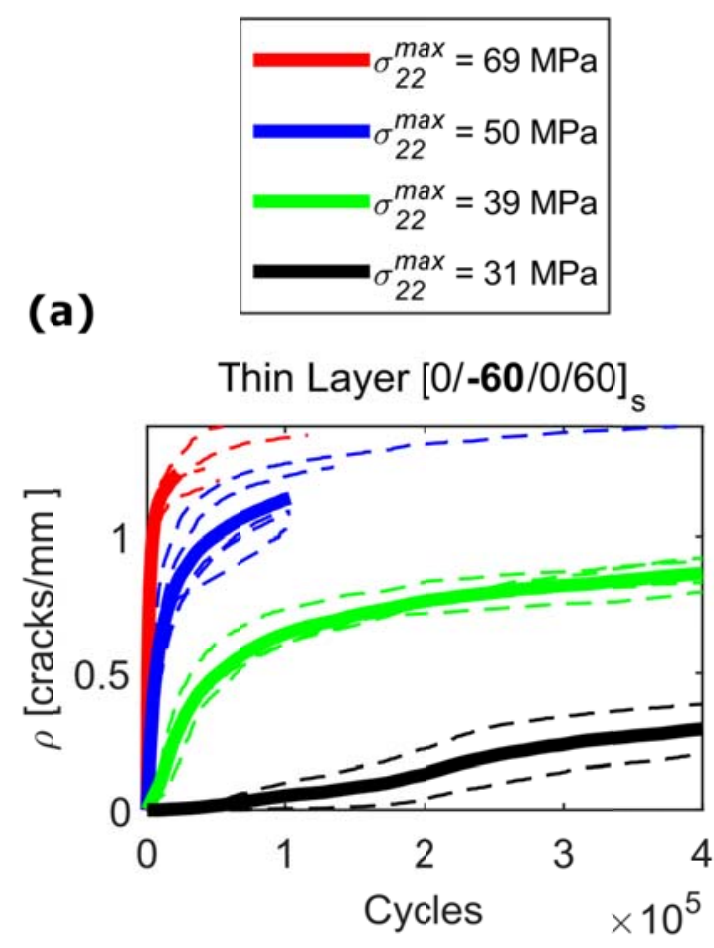

(b) Thick Layer $[0 /-60 / 0 / 60]_{s}$

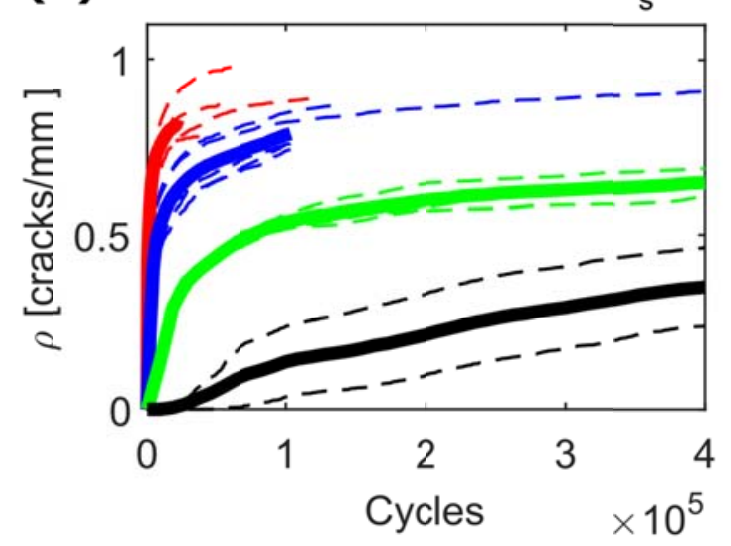

Figure 2: Crack density measured using ACC during fatigue tests ( $T-T C A)$ for (a) the thin layer and (b) the thick layer. Dashed lines represent a single test and bold lines represent average crack density for each stress level.
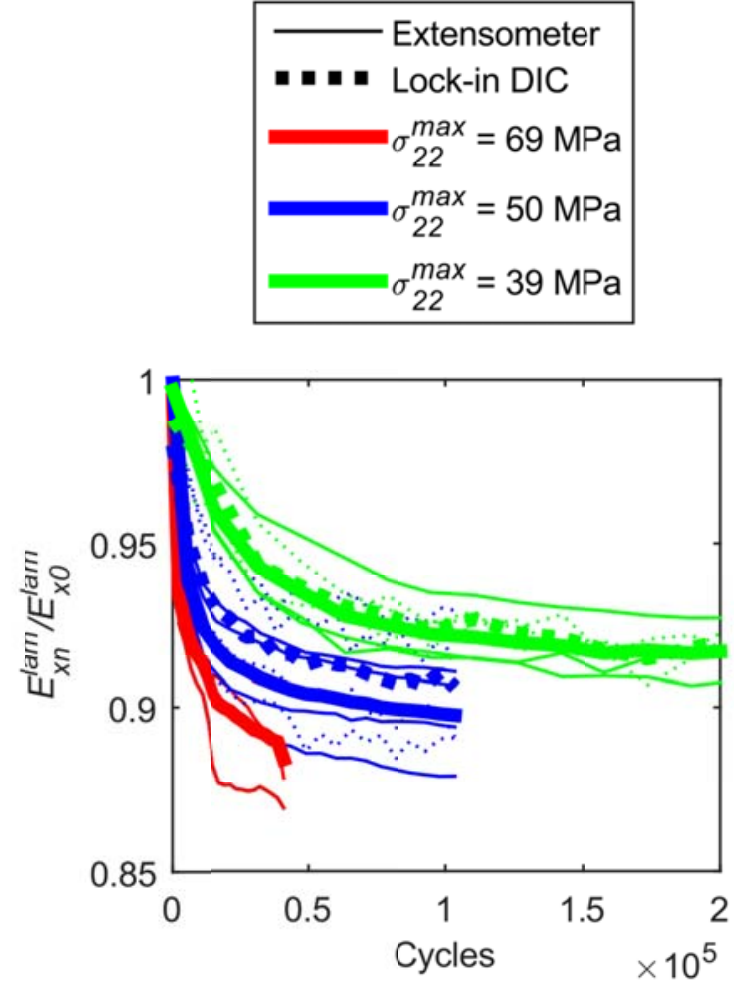

Figure 3: Stiffness degradation during fatigue tests (T-T CA) monitored using lockin DIC (dotted lines) and extensometer (full lines). Thin lines represent a single test and bold lines represent an average for all tests at a given load level. 

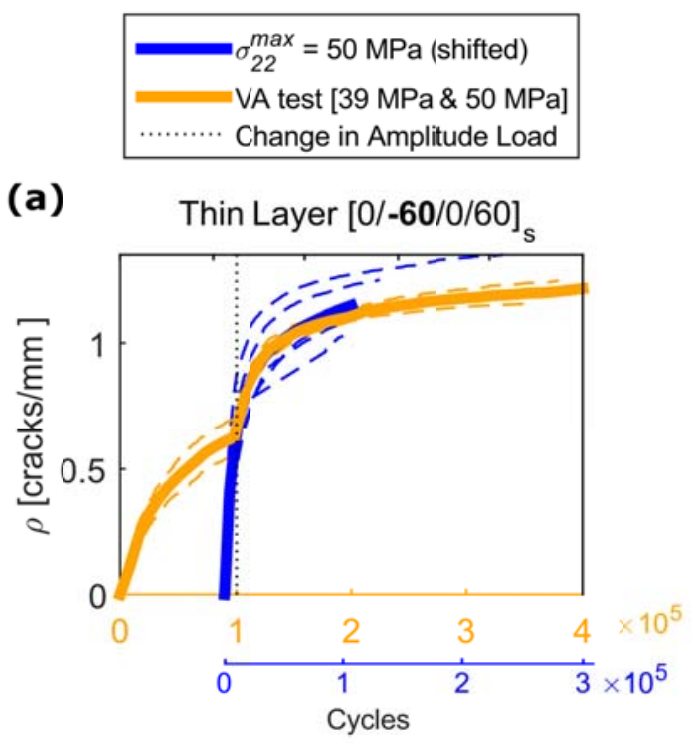

(b)

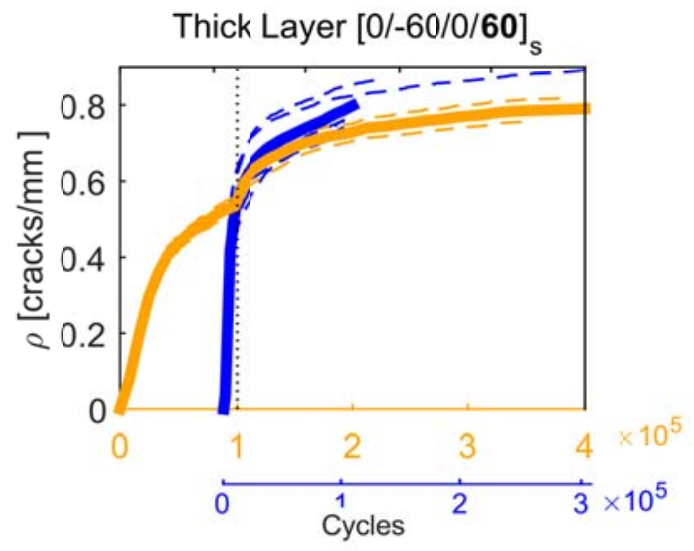

Figure 4: Crack density measured during

T-T VA fatigue tests compared to T-T CA fatigue tests at a stress level of 50MPa.

The CA test results have been shifted such that the blue axis denotes the number of cycles. Dashed lines represent a single test and bold lines represent average crack density for each stress level.

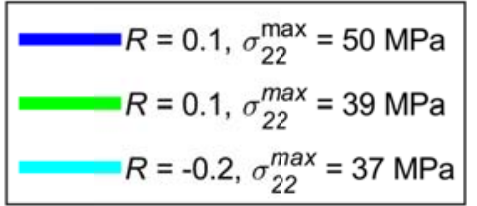

Thin Layer $[0 /-60 / 0 / 60]_{\mathrm{s}}$
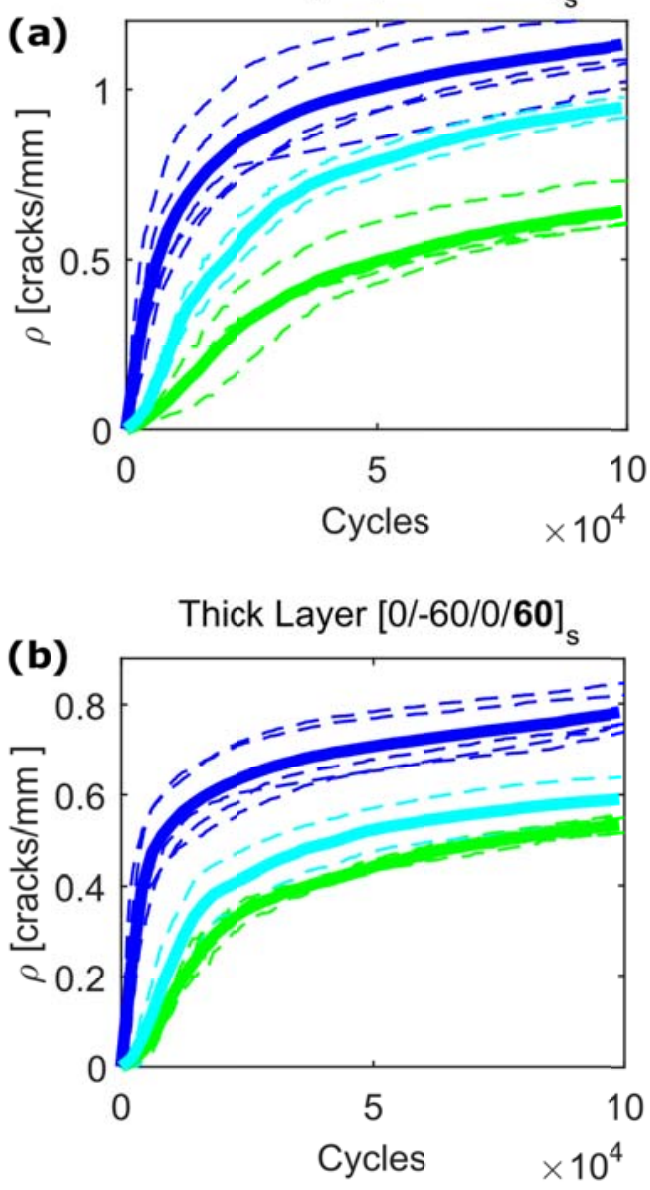

Figure 5: Measured crack density for C-T CA compression-tension fatigue tests compared to T-T CA tension-tension fatigue tests. Dashed lines represent a single test and bold lines represent average crack density for each stress level. 
(a)

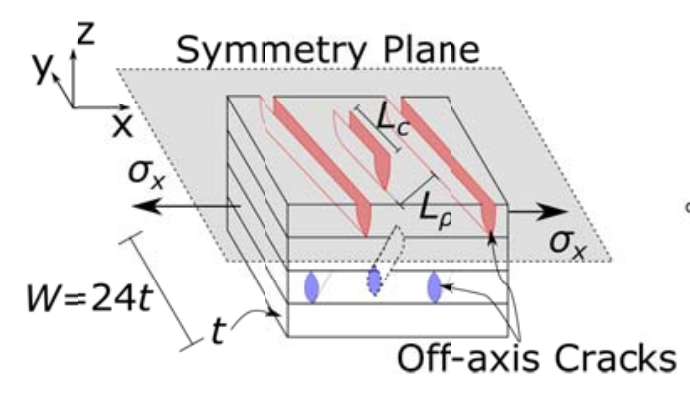

(b)
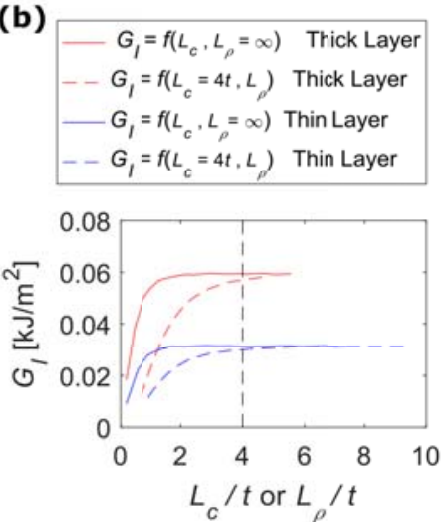

(C)
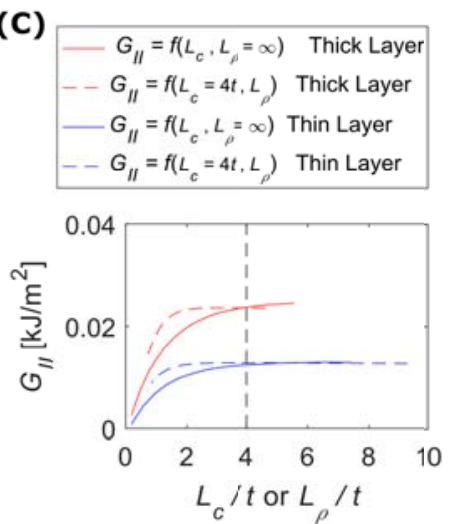

Figure 6: (a) Illustration of the unit-cell model along with important geometrical parameters and (b) the mode I ERR and (c) the mode II ERR for isolated off-axis cracks and interacting cracks with $\sigma_{x}=100 \mathrm{MPa}$. The mode I and mode II ERR have been computed using the VCCT approach.

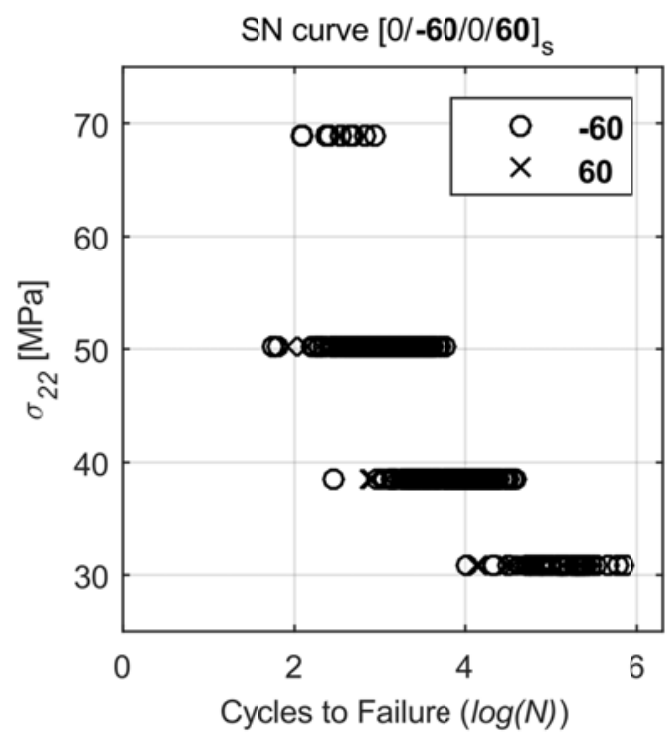

Figure 7: S-N diagram for initiation of isolated off-axis cracks. 
(a)

$$
\begin{array}{r}
-\sigma_{22}^{\max }=50 \mathrm{MPa} \\
\sigma_{22}^{\max }=39 \mathrm{MPa} \\
\sigma_{22}^{\max }=31 \mathrm{MPa}
\end{array}
$$

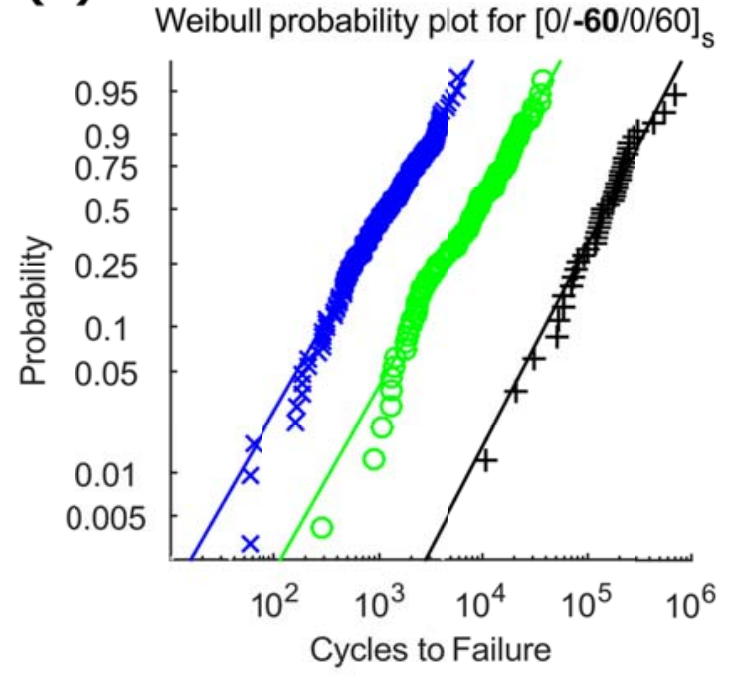

(b) Weibull Probability plot for $[0 /-60 / 0 / 60]_{\mathrm{S}}$

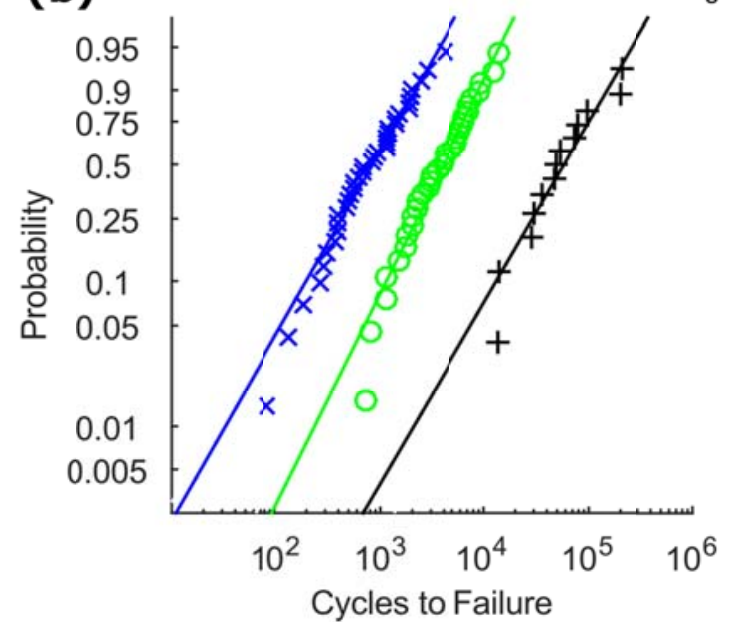

Figure 8: Data for the initiation of isolated cracks from Figure 7 replotted in a Weibull probability plot.

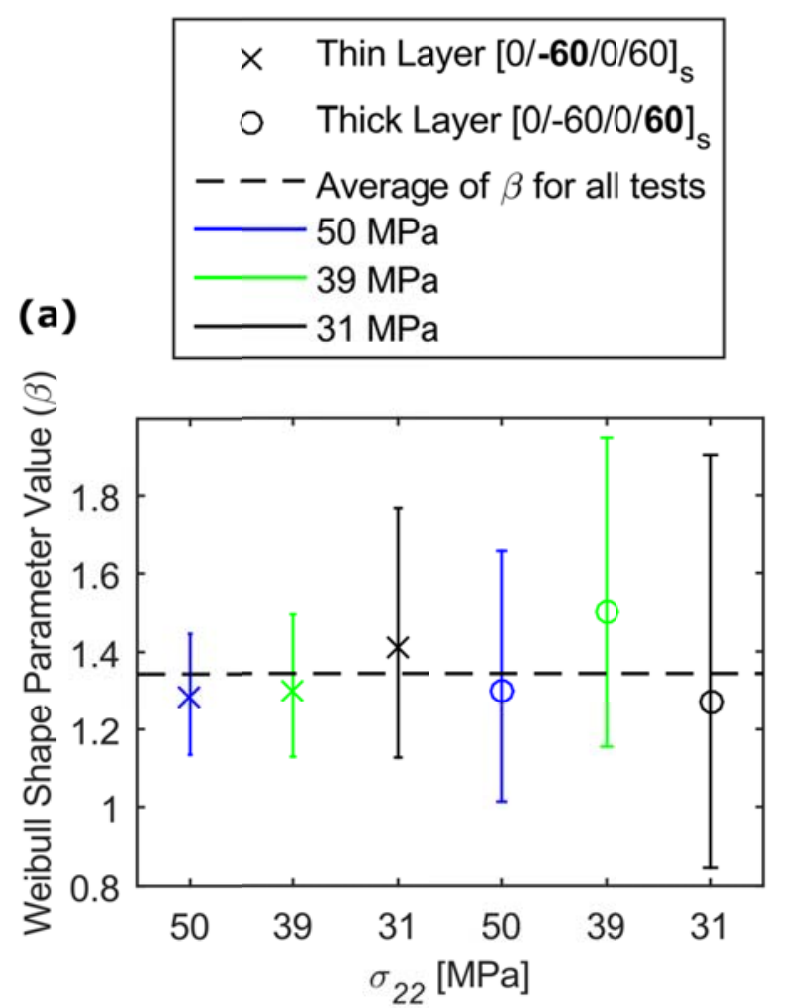

(b)

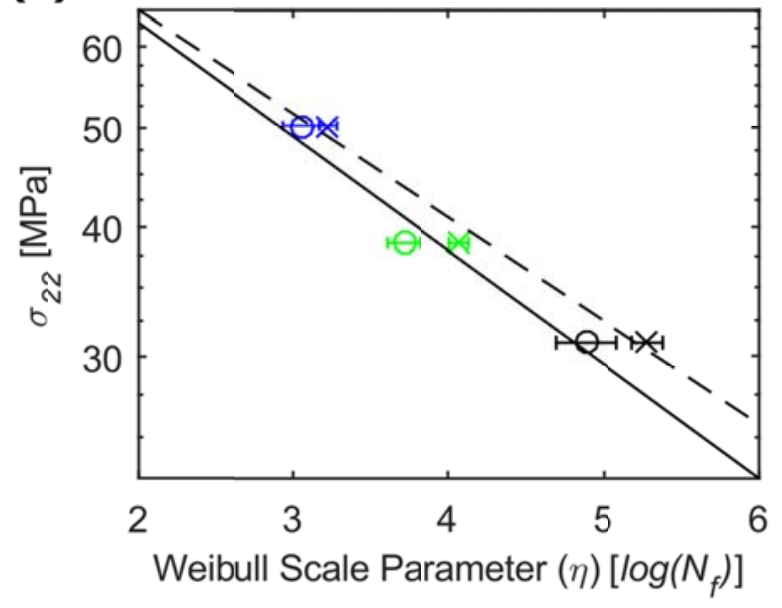

Figure 9: Maximum likelihood estimates along with $0.05 \%$ and $95 \%$ confidence bounds for (a) the shape parameter, and (b) the scale parameter. 
(a)

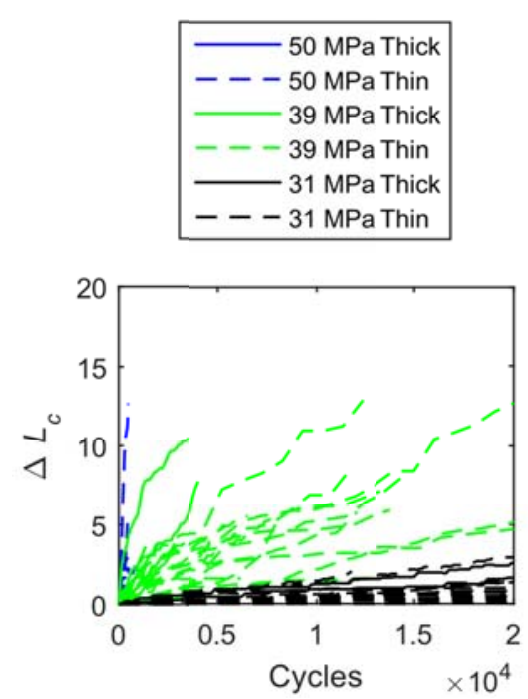

(b)
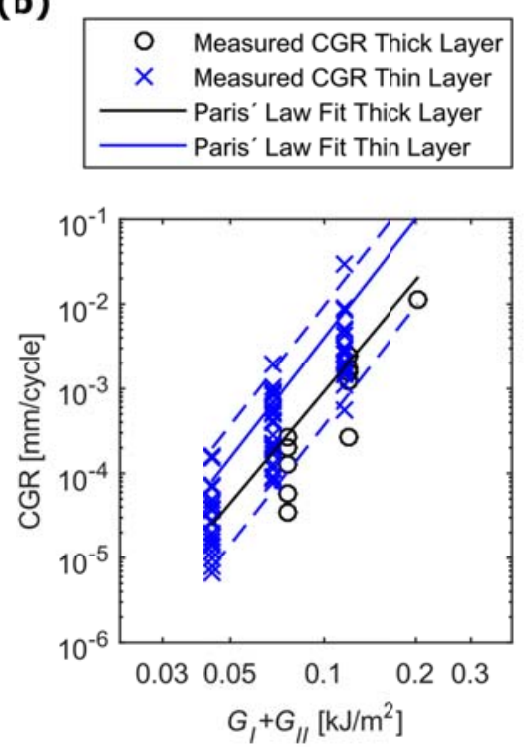

(c)

$$
\begin{aligned}
& ---\sigma_{22}^{\max }=50 \mathrm{MPa} \\
& ---\sigma_{22}^{\max }=39 \mathrm{MPa} \\
& ---\sigma_{22}^{\max }=31 \mathrm{MPa}
\end{aligned}
$$

Weibull probability plot CGR in $[0 /-60 / 0 / 60]_{S}$

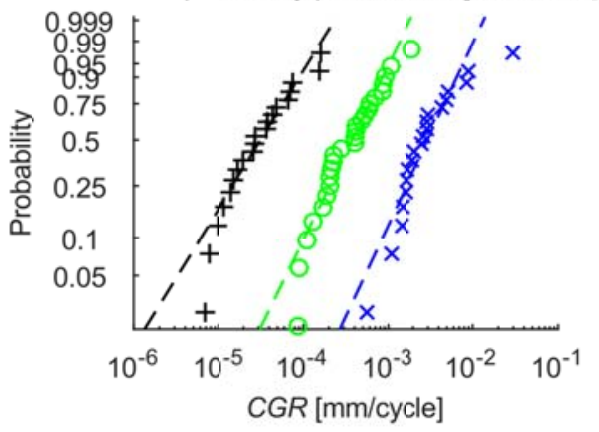

Figure 10: a) measured change in crack length as function of cycles for isolated edge cracks, b) crack growth rate as function of total ERR with Paris' Law relationship fitted to the data and c) CGR data for the thin layer plotted in a Weibull probability plot.
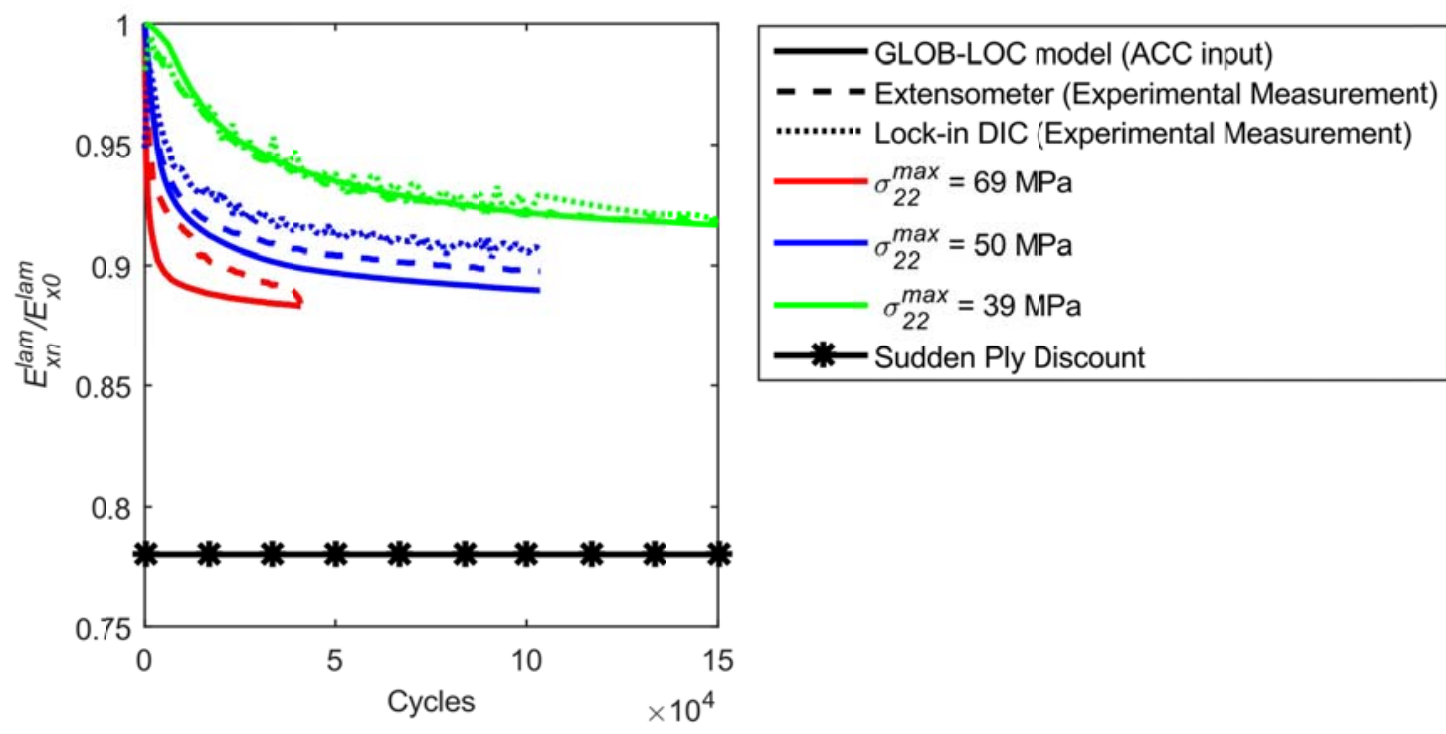

Figure 11: Benchmark of stiffness degradation modelling using the GLOB-LOC model (based on ACC input) and the sudden ply discount degradation. 